Chemical, Petroleum and Environmental Engineering

\title{
The Catholyte Effects on The Microbial Desalination Cell Performance of Desalination and Power Generation
}

\author{
Suhad Shamil Jaroo * \\ MSc. \\ Civil Engineering Department - \\ University of Technology \\ Baghdad - Iraq \\ 42102@student.uotechnology.edu.iq
}

\author{
Ghufran Farooq Jumaah \\ Dr. \\ Civil Engineering Department - \\ University of Technology \\ Baghdad - Iraq \\ 40129@uotechnology.edu.iq
}

\section{Talib Rashid Abbas \\ Dr.}

Environment and Water

Directorate - Ministry of Science

and Technology

Baghdad - Iraq

talibrshd@yahoo.com

\begin{abstract}
A microbial desalination cell (MDC) is a new approach of bioelectrochemical systems. It provides a more sustainable way to electrical power production, saltwater desalination, and wastewater treatment at the same time. This study was examined three operation modes of the MDC; they are chemical cathode, air cathode, and biocathode MDC to give clear sight of this system's performance. The experimental work results for these three modes were recorded as power densities generation, saltwater desalination rates, and COD removal percentages. For the chemical cathode MDC, the power density was $96.8 \mathrm{~mW} / \mathrm{m}^{2}$, the desalination rate was $84.08 \mathrm{ppm} / \mathrm{hr}$, and the COD removal percentage was $95.94 \%$. The air cathode MDC results were different; the power density was $24.2 \mathrm{~mW} / \mathrm{m}^{2}$, the desalination rate was $86.11 \mathrm{ppm} / \mathrm{hr}$, and the COD removal percentage was $91.38 \%$. The biocathode MDC results were 19.91 $\mathrm{mW} / \mathrm{m}^{2}$ as the power density, $88.9 \mathrm{ppm} / \mathrm{hr}$ as the desalination rate, and $96.94 \%$ as the COD removal percentage. The most efficient type of MDC in this study in power production was the chemical cathode MDC, but it is the lowest sustainable. On the other hand, the biocathode MDC was the best in desalination process performance and both the air cathode and biocathode MDC are more sustainable and environmentally friendly, especially the biocathode MDC.
\end{abstract}

Keywords: MDC, chemical cathode, air cathode, biocathode, power generation.

*Corresponding author

Peer review under the responsibility of University of Baghdad.

https://doi.org/10.31026/j.eng.2021.07.05

2520-3339 () 2019 University of Baghdad. Production and hosting by Journal of Engineering. This is an open access article under the CC BY4 license http://creativecommons.org/licenses/by /4.0/). Article received:2/3/2021

Article accepted: 21/4/2021

Article published:1/7/2021 


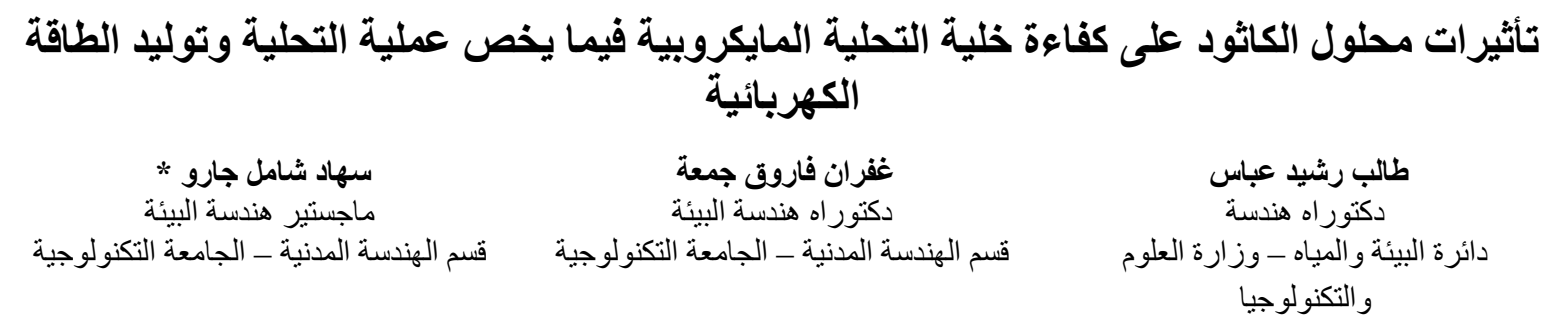

الخلاصة

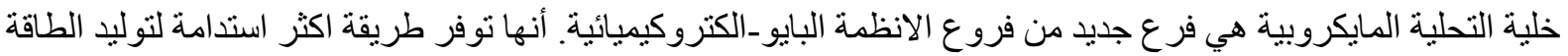

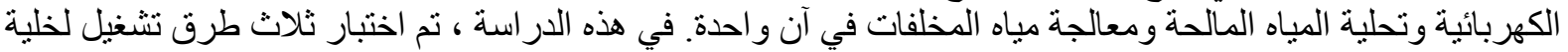

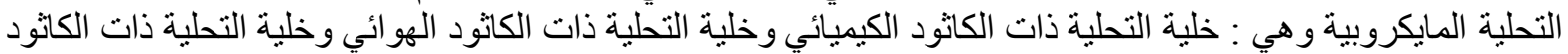

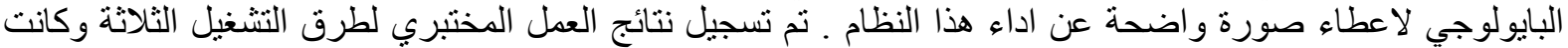

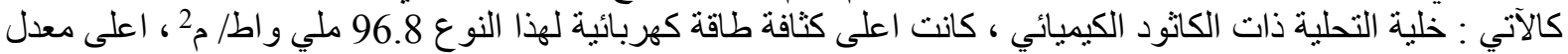

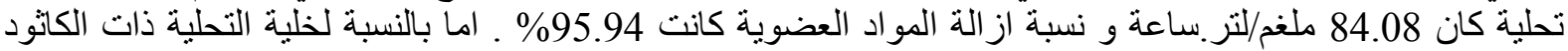

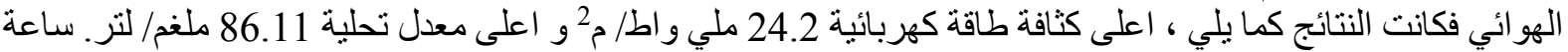

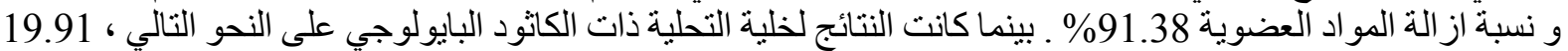

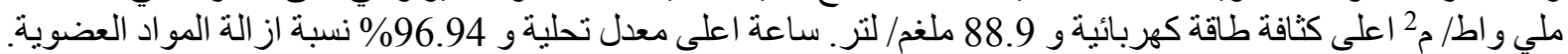

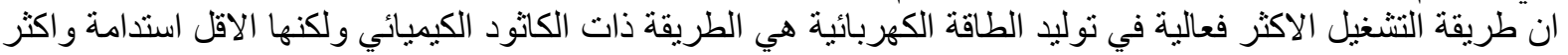

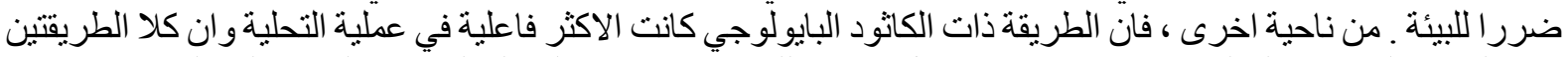

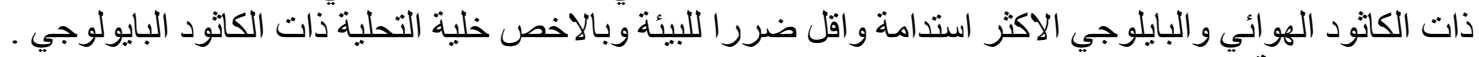

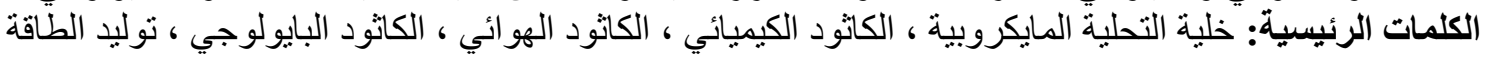

\section{INTRODUCTION}

The world suffers from the increasing urban water shortage, so water reuse and desalination became necessary and useful in many countries, especially Iraq. The technologies of wastewater treatment and desalination are costly and energy-waste. For example, the most common wastewater treatment process is the activated sludge process, requiring high capital and maintenance costs in addition to large amounts of energy (Gude, 2015b). Conventional desalination technology expends large amounts of energy too. The most efficient seawater desalination system is the reverse osmosis process, and the energy required to accomplish this process of only $1.8-2.2 \mathrm{kWh} / \mathrm{m}^{3}$. For that, there is a persistent need to progress new and proceeding water purification technologies with low cost for both wastewater treatment and desalination purposes to increase freshwater supplies (Gude, 2017, 2018).

Bioelectrochemical systems (BES) have shown promise for energy production and efficient way for wastewater treatment. As one of BES, the microbial fuel cells (MFC) have taken much concern in current years (Friman et al., 2013, Gude, 2016). The bioelectricity was generated by MFCs directly from organic matter's biodegradation in wastewater by anaerobic bacteria (Mathuriya, 2016). Low to the high strength of wastewaters can be remedied by this technology, at much lower biosolid generation with high conversion efficiencies (Gude, 2015b, 2016). MFC's modification is a microbial desalination cell (MDC), the technique for wastewater treatment and desalination with bioelectricity generation at the same time (Cao et al., 2009). This technique is under expansion by many researchers. The MDC working theory is based on bioelectrochemical systems (BESs) to transform wastewater into treated effluent with bioelectricity generation and desalination process by the ions transformation. MDC consists of three chambers; they are anode, desalination, and cathode chambers. In the anode 
chamber, an anaerobic environment is perfect for the biodegradation of many types of wastewater (by the organic materials' oxidation process).

In contrast, the clean electron acceptors thrift as catholyte exists a recent issue in bioelectrochemical systems. Many types of catholyte can be utilized, chemical materials, for example, ferricyanide and permanganate, were being used as catholyte, but these are costly and toxic to the environment, so replacement is requiring (Cao et al., 2009) because these chemicals are not sustainable when used as electron acceptors in large-scale applications.

Oxygen is another type of electron acceptor with a high reduction potential and availability, so it was recognized as a functional terminal electron acceptor (TEA). The cathodes utilizing oxygen as the TEA are known as air cathodes, but this cathode's disadvantage is the slower redox kinetics under ambient conditions. Therefore, costly catalyst components such as platinum are utilized to diminish the activation overpotential attached to oxygen reduction and the energy-requiring to run mechanical tools used to preserve the air cathode's optimal concentration of dissolved oxygen.

Many of the prior MDC intended to supply the cathode chamber airing and retrieve power generating benefits by power exhaustion for airing (Werner et al., 2013). Therefore, biocathodes are the active oxygen produce methods that can be a sustainable solution to cure this issue. Microorganisms are utilized in biocathodes as biocatalysts to be accepted electrons instead of noble or nonnoble catalysts. Therefore, this cathode can be deemed a more economically and sustainable method of bioelectrochemical systems (Huang et al., 2011).

Many researchers studied the characteristics and operation conditions of MDC with different types of catholyte. For example, Cao et al. (2009) were among the first researchers to investigate a new method to desalinate saltwater by microbial desalination cell. The chemical cathode was used in this research. The results collected in this study illustrate that an MDC is suitable for saltwater desalination, whether at a salt concentration equal to or higher than 35 $\mathrm{g} / \mathrm{L}$ (Cao et al., 2009). Luo et al. (2012) studied the ions' installation and migration mechanisms in microbial desalination cell. The air cathode was utilized in this study. It showed MDC performance's sensibility to the ion species' installation and various transport mechanisms found in the saltwater (Luo et al., 2012). Ping et al. (2013) utilized air cathode MDC to study cation and anion exchange membranes scaling and fouling, respectively, in microbial desalination cells (Ping et al., 2013). Bahareh and Veera (2013) and (2015) studied the biocathode microbial desalination cells (PMDCs) for clean water, energy, and biomass product. The study confirmed the performance of algae biocathodes for in situ oxygen generation. It gave an environmentally acceptable approach in which algae can operate as an in-situ oxygen generator and help remove COD in the cathode chamber (Bahareh and Veera, 2013, 2015).

This study aims to investigate the best way to operate the MDC system by many experiments with a different type of catholyte and recording the characteristics and working conditions of all MDC types presented by saltwater desalination system performance, wastewater treatment, and electric power generation.

\section{MATERIALS AND METHODS}

\subsection{Consistency}

For all operation modes (chemical cathode, air cathode, and biocathode), the MDC configuration consists of cathode and anode with the middle's desalination chamber of plexiglass. The cathode and anode's internal cross-section area were $10 \times 10 \times 7 \mathrm{~cm}$, and the 
desalination chamber has an inner cross-section area of 10x10x3 cm (Suhad et al., 2019) as described in Fig. 1-A. Two types of ion-exchange membranes supplied from Membrane International Ltd. were used, anion exchange membrane (AEM, AMI 7001) and cation exchange membrane (CEM, CMI 7000). The AEM was located between the anode and desalination chambers; the CEM was located between the cathode and desalination chambers. Before use, the membranes were preconditioned for $24 \mathrm{~h}$ by flooding in a $5 \%$ salt $(\mathrm{NaCl})$ solution and swilled with deionized water as recommended by the supplier to allow membrane hydration and expansion. The anode and cathode were made of graphite sheets; each has a 9x9 $\mathrm{cm}$ (length $\mathrm{x}$ width) dimension and $2 \mathrm{~mm}$ (thickness). The distance between each electrode and the adjacent membrane was $1 \mathrm{~cm}$. Copper filaments with sealed contact were utilized to connect the external resistance to the electrodes.

All chambers were provided with inlet and outlet ports of $1 \mathrm{~cm}$ in diameter; except the cathode chamber has a $3 \mathrm{~cm}$ diameter inlet port suitable for dissolved oxygen (DO) meter, and the anode chamber was sealed from ambient air to attain the required anaerobic conditions. The anolyte and catholyte volume was $650 \mathrm{~mL}$, while the desalination chamber solution volume was $300 \mathrm{~mL}$. The MDC is shown in Fig. 1-B.
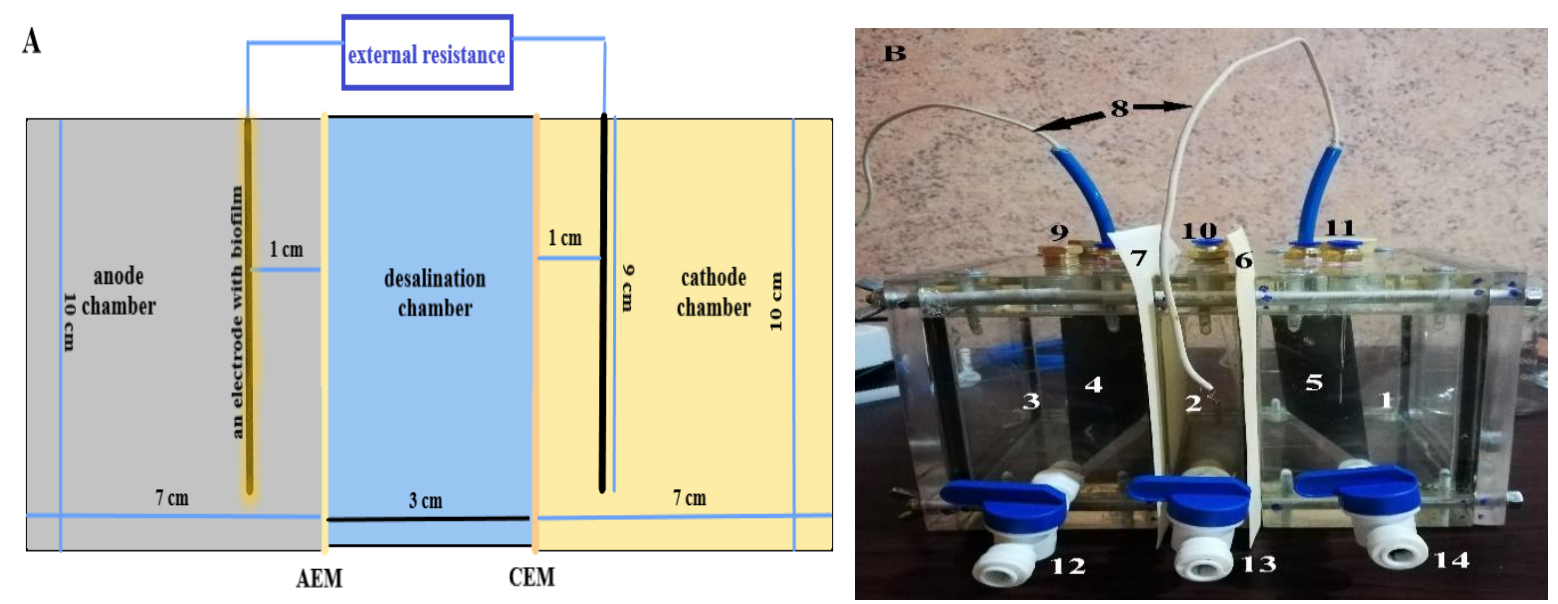

Figure 1. A- Graphic diagram of the MDC and B- The MDC (1. Cathode chamber, 2. Desalination chamber, 3. Anode chamber, 4,5. The electrodes, 6,7. CEM and AEM, respectively, 8. Copper Filaments, 9,10,11. Inlets, and 12,13,14. Outlet).

\subsection{The Materials and Method}

In this study, three MDC types were investigated (chemical cathode, air cathode, and biocathode MDC) in three experiments for six days to each experiment. The same anolyte and the same saltwater concentration were used for the three experiments. In contrast, the catholyte was different for each experiment. Next to the details of all materials were used in this study.

\subsubsection{Microbial culture}

the activated sludge from the Al-Rustomia wastewater treatment plant in Baghdad city was used as the microbial culture to seed the anode chamber; it was adapted in the anode chamber with an anaerobic condition for approximately one month before experiments beginning to form a biofilm layer on the electrode; during the biofilm formation period, the development in biofilm thickness was observed by open-circuit voltage generation recorded. 


\subsubsection{Anolyte solution}

The synthetic wastewater was used in the anode chamber with $1600 \mathrm{mg} / \mathrm{L}$ of sodium acetate and buffer solution to stabilize the anode chamber's $\mathrm{pH}$; its ingredients are listed in Table (1) (Cao et al., 2009). Trace mineral solution $(10 \mathrm{ml})$ was added in addition to a buffer solution (Pratiksha et al., 2015), and its ingredients are listed in Table (1) also. The preparation of these solutions was done by dissolving materials in (1L) of deionized (DI) water.

Table 1. The buffer solution components and trace mineral solution in the anode chamber.

\begin{tabular}{|c|c|c|c|}
\hline \multicolumn{2}{|c|}{ Buffer solution } & \multicolumn{2}{c|}{ Trace mineral solution } \\
\hline Material & Concentration mg/L & Material & Concentration mg/L \\
\hline $\mathrm{K}_{2} \mathrm{HPO}_{4} .3 \mathrm{H}_{2} \mathrm{O}$ & 20 & $\mathrm{CaCl}_{2} .6 \mathrm{H}_{2} \mathrm{O}$ & 150 \\
\hline $\mathrm{KH}_{2} \mathrm{PO}_{4}$ & 20 & $\mathrm{H}_{3} \mathrm{BO}_{3}$ & 150 \\
\hline $\mathrm{NH}_{4} \mathrm{Cl}$ & 200 & $\mathrm{CuSO}_{4} .5 \mathrm{H}_{2} \mathrm{O}$ & 30 \\
\hline $\mathrm{CaCl}_{2} .2 \mathrm{H}_{2} \mathrm{O}$ & 40 & $\mathrm{ZnSO}_{4} .7 \mathrm{H}_{2} \mathrm{O}$ & 120 \\
\hline $\mathrm{MgCl}$ & & $\mathrm{FeCl}_{3} .6 \mathrm{H}_{2} \mathrm{O}$ & 1500 \\
\hline $\mathrm{KCl}$ & 40 & $\mathrm{KI}$ & 30 \\
\hline
\end{tabular}

\subsubsection{Saltwater solution}

The preparation of saltwater solution was done by dissolving $\mathrm{NaCl} 35 \mathrm{~g} / \mathrm{L}$ in DI water to imitate seawater for three operation modes (chemical cathode, air cathode, and biocathode MDC).

\subsubsection{Catholyte solution}

Chemical cathode MDC: The catholyte of this operation mode consists of Potassium Ferricyanide $\left(\mathrm{K}_{3}\left[\mathrm{Fe}(\mathrm{CN})_{6}\right]\right)(16.5 \mathrm{~g} / \mathrm{L})$ with $\mathrm{KH}_{2} \mathrm{PO}_{4}(2.25 \mathrm{~g} / \mathrm{L})$ and $\mathrm{K}_{2} \mathrm{HPO}_{4} .3 \mathrm{H}_{2} \mathrm{O}(2 \mathrm{~g} / \mathrm{L})$ as a buffer solution (Cao et al., 2009). The preparation of this catholyte was done by dissolving materials in (1L) of DI water.

* Air cathode MDC: The catholyte of this operation mode consists of deionized water with tap water (50 to $50 \%$ ) without a buffer solution.

* Biocathode MDC: The catholyte of this operation mode consists of microalgae culture and its growth media with the same components of the buffer solution was used with the chemical cathode operation mode.

a. Algal culture: The microalgae Chlorella Vulgaris were obtained from the online market (Suncoast marine aquaculture, SCMAlabs.com), which were utilized as microalgae culture in this study for a biocathode operation mode with $300 \mathrm{~mL}$ as the microalgae culture concentration the catholyte solution.

b. Algal growth media: The growth medium components for algae with trace mineral solution were used in this study are listed in Table (2) (Bahareh and Veera, 2015). The growth 
medium's preparation was done by dissolving materials in (1L) of DI water with adding $(3 \mathrm{~mL})$ of trace mineral solution. An inorganic carbon source was necessary to progress the photosynthetic process of algae and, therefore, increase oxygen production, so $(0.5 \mathrm{~g} / \mathrm{L})$ of $\mathrm{NaHCO} 3$ was added to the catholyte in this operation mode (Thomas and Veera, 2018). The algae illumination in the biocathode section was done by a white light electrical lamp $(23 \mathrm{~W})$. This lighting is necessary to complete the algae photosynthetic process and oxygen production.

Table 2. The algal growth medium components with trace mineral solution.

\begin{tabular}{|c|c|c|c|}
\hline \multicolumn{2}{|c|}{ Growth medium } & \multicolumn{2}{c|}{ Trace mineral solution } \\
\hline Material & Concentration $\mathrm{mg} / \mathrm{L}$ & Material & Concentration $\mathrm{mg} / \mathrm{L}$ \\
\hline $\mathrm{KH}_{2} \mathrm{PO}_{4}$ & 105 & $\mathrm{CoCl}_{2}$ & 160 \\
\hline $\mathrm{K}_{2} \mathrm{HPO}_{4} .3 \mathrm{H}_{2} \mathrm{O}$ & 75 & $\mathrm{MnCl}_{2}$ & 82 \\
\hline $\mathrm{NaCl}$ & 25 & $\mathrm{FeCl}_{3} .6 \mathrm{H}_{2} \mathrm{O}$ & 194 \\
\hline $\mathrm{CaCl}_{2} .2 \mathrm{H}_{2} \mathrm{O}$ & 25 & $\mathrm{Na}_{2} \mathrm{MoO}_{4} .2 \mathrm{H}_{2} \mathrm{O}$ & 8 \\
\hline $\mathrm{MgSO}_{4}$ & 75 & $\mathrm{ZnCl}_{2}$ & 5 \\
\hline $\mathrm{NaNO}_{3}$ & 250 & & \\
\hline
\end{tabular}

\subsection{Analyses and Calculations}

A digital multimeter (Aswar, DT860D) was used to record the voltage with a $100 \Omega$ external resistance was used in closed circuit tests to connect the anode and the cathode. Ohm's law determined the electric stream, $\mathrm{I}=\mathrm{E} / \mathrm{R}$, where $\mathrm{E}$ is the voltage and $\mathrm{R}$ is the external resistance. The power density was studied as per the electrode surface area. The coulombic efficiency (CE), a portion of the electrons recovered as an electric stream from the substrate, was estimated using eq. (1) (Logan et al., 2006):

$C E=\frac{M \cdot \int_{0}^{t} I d t}{n \cdot F \cdot V_{a} \cdot\left(C O D_{0}-C O D_{t}\right)} \times 100 \%$

Where:

CODo $=$ initial anolyte chemical oxygen demand $\mathrm{g} / \mathrm{L}$.

$\mathrm{CODt}=$ the COD value after the time $(\mathrm{t}) \mathrm{g} / \mathrm{L}$.

$\mathrm{F}=$ Faraday's constant $(96485 \mathrm{C} / \mathrm{mol})$.

$\mathrm{I}=$ the electric current A.

$\mathrm{M}=$ the oxygen molecular weight $\mathrm{g} / \mathrm{mol}$.

$\mathrm{n}=4$ the electrons numbering mutual per mole of oxygen.

$\mathrm{Va}=$ the anolyte volume $\mathrm{L}$.

The MDC was operated to reach a steady state. The polarization curves were determined with the aid of variable external resistance ranged from $10 \mathrm{k} \Omega$ to $100 \Omega$ in steps (leaving about 20 min between successive steps to attain a steady-state) (Bahareh and Veera, 2015). The COD was measured by utilizing a standard method of reactor digestion method. The multimeter 
(Lovi Bond Senso Direct 150) was used to measure TDS, Electrical conductivity, DO in the cathode chamber, and $\mathrm{pH}$ of the samples. The TDS removal rate was calculated as follows:

$T D S_{\text {removal rate }}(\mathrm{ppm} / \mathrm{h})=\left(\frac{C_{0}-C_{t}}{t}\right)$

Where:

$\mathrm{C}_{0}$ and $\mathrm{C}_{\mathrm{t}}=$ the initial and the final TDS of saltwater in the desalination chamber over a batch cycle of time $t$ as ppm.

\section{RESULTS AND DISCUSSION \\ 3.1 Electrical Power Production}

Fig. 2 illustrates the three experiments' voltage and power density values with the different operation modes. At the beginning of each experiment, the three chambers were fed with the solutions was shown in section (2.2). These two figures show that the maximum voltage difference between the electrodes in the anode and cathode chamber for a fixed value of the external electrical resistance at $100 \Omega$ was $280 \mathrm{mV}, 140 \mathrm{mV}$, and $127 \mathrm{mV}$ for the chemical cathode, air cathode, and biocathode MDC, respectively; for six days of each experiment. Similarly, the maximum power density was $96.8,24.2$, and $19.91 \mathrm{~mW} / \mathrm{m}^{2}$ for the chemical cathode, air cathode, and biocathode MDC. The voltage and power density values increased at the beginning over time until they reach the maximum value. After that, the values dropped over time due to the substrate's depletion in the anode chamber.

A

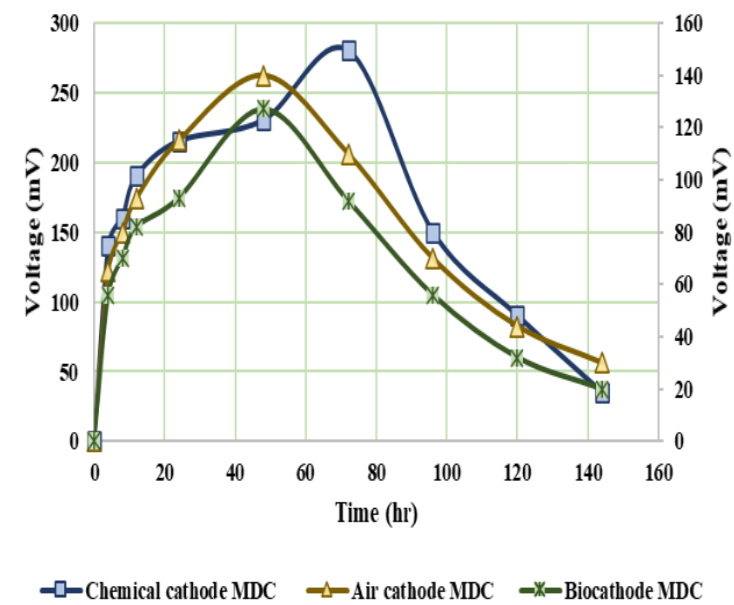

B

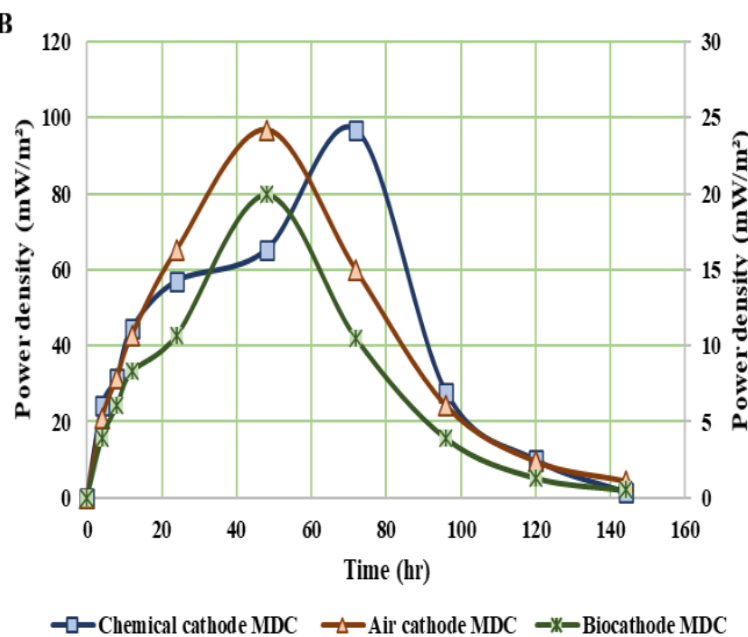

Figure 2. A- The voltage values vs. time, and B- The power density values vs. time for the three operation modes.

It is clear that the chemical cathode MDC was the most effective in electrical power generation and that due to using the Potassium Ferricyanide solution as catholyte is a powerful catalyst agent. On the other hand, the biocathode MDC was the lowest effective in electrical power generation due to the oxygen production dropping from algae during the dark period, so the electric power generation dropped. Fig. 3 illustrates the contrast in electric power generation between the light and dark periods of biocathode MDC. 


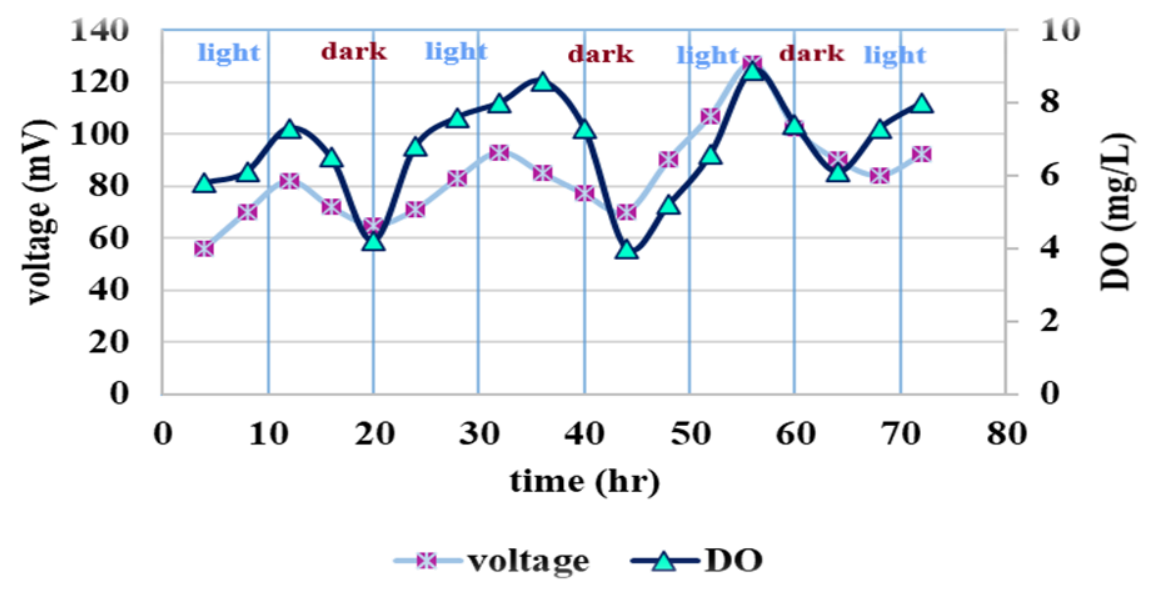

Figure 3. The voltage generation values with different dissolved oxygen values during light and dark periods for biocathode MDC.

After reaching each operation mode steady-state operation, the polarization curve and voltage profiles were drawn using the way presented in section (2.3) (Bahareh and Veera, 2015), and they were illustrated in Fig. 5. While the voltage values vs. multi resistance for the three operation modes as shown in Fig. 4. The highest power density values were 70.5, 26.7, and 9.7 $\mathrm{mW} / \mathrm{m}^{2}$ for the chemical cathode, air cathode, and biocathode MDC.

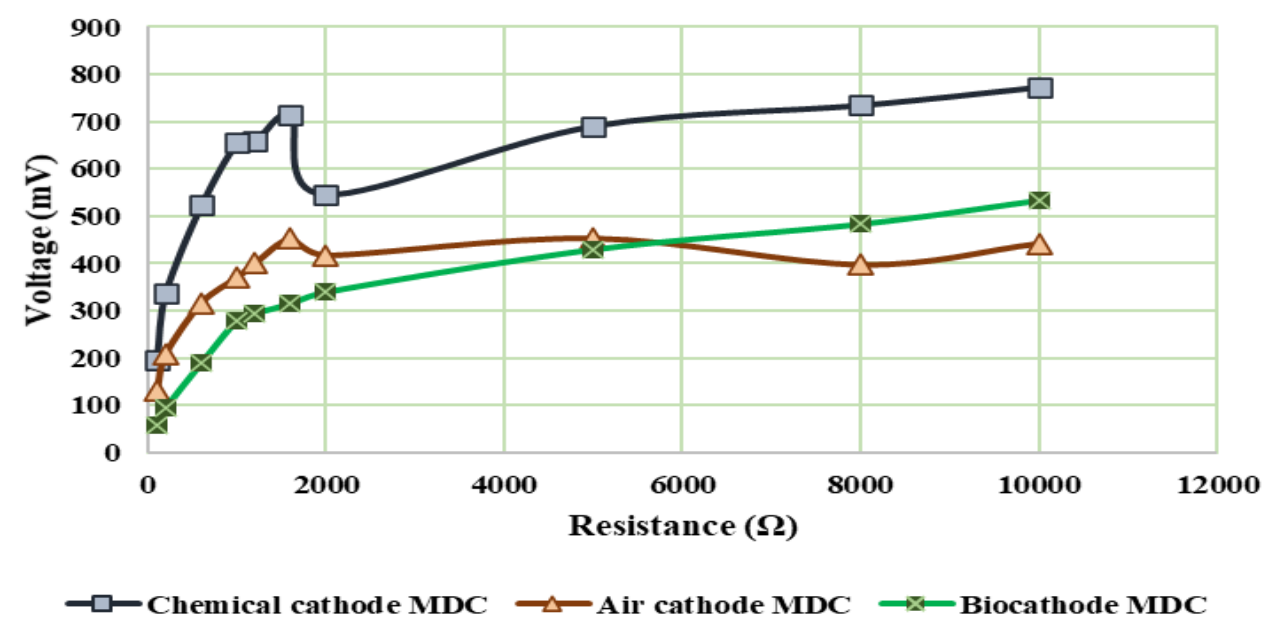

Figure 4. The voltage values vs. multi-resistance for the three operation modes. 


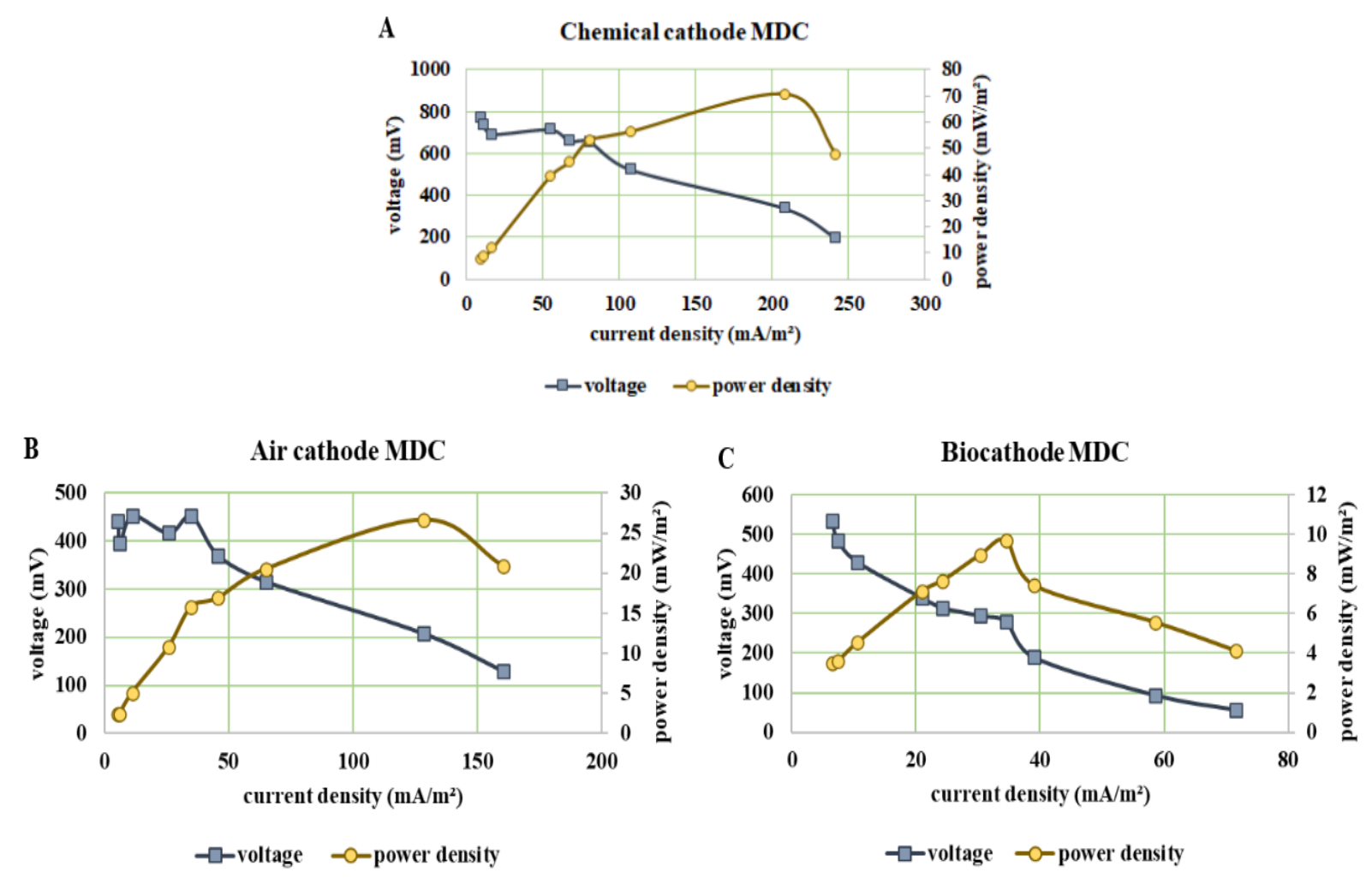

Figure 5. The polarization curves and voltage profiles for the three operation modes.

\subsection{Saltwater Desalination Efficiency}

Fig. 6 illustrates the salt removal rates for the three operation modes of MDC in this study; they were $84.08,86.11,88.9 \mathrm{ppm} / \mathrm{hr}$ for the chemical cathode, air cathode, and biocathode MDC. They were convergent for the three cases but the lowest value of the chemical cathode MDC due to its lower potential difference between the anode and cathode which affects the migration of ions from the middle chamber to the anode and cathode chamber (Bahareh and Veera, 2013). On the other hand, the biocathode MDC had the highest value of salt removal rate, and that occurred in the study of Bahareh and Veera, 2013 which investigated the difference between air cathode and biocathode MDC performance, the biocathode MDC more efficient in salinity removal. Fig. 7 shows the changes in the catholyte's $\mathrm{pH}$ values and the anolyte due to the three operation cases' desalination process. The changes in the $\mathrm{pH}$ value of the anolyte and catholyte for the chemical cathode and biocathode MDC and the anolyte of the air cathode MDC were so slightly due to the effect of the buffer solution in the cathode and anode chamber for these operation modes. On the other hand, the catholyte of the air cathode MDC became more alkaline with time because the catholyte was without buffer solution; the catholyte's $\mathrm{pH}$, in this case, changed from 7.5 to 8.95. The change in the catholyte's $\mathrm{pH}$ of the chemical cathode MDC decreased with time. That change is not like the change in the air cathode and biocathode MDC; it is increased for these operation modes, and that might be attributed to forming HCN in the catholyte of chemical cathode MDC (MSDS for potassium ferricyanide). 


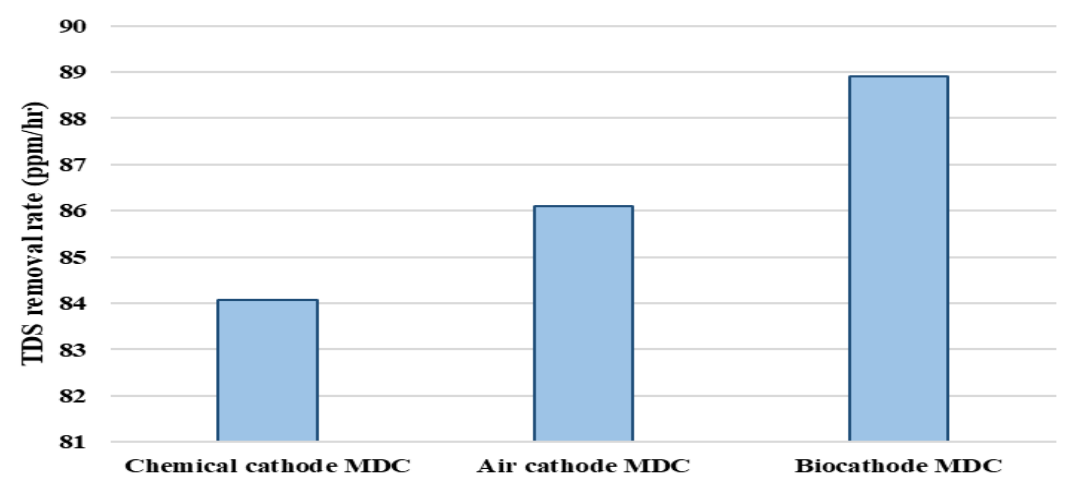

Figure 6. The TDS removal rates of the MDC with the three operation modes.
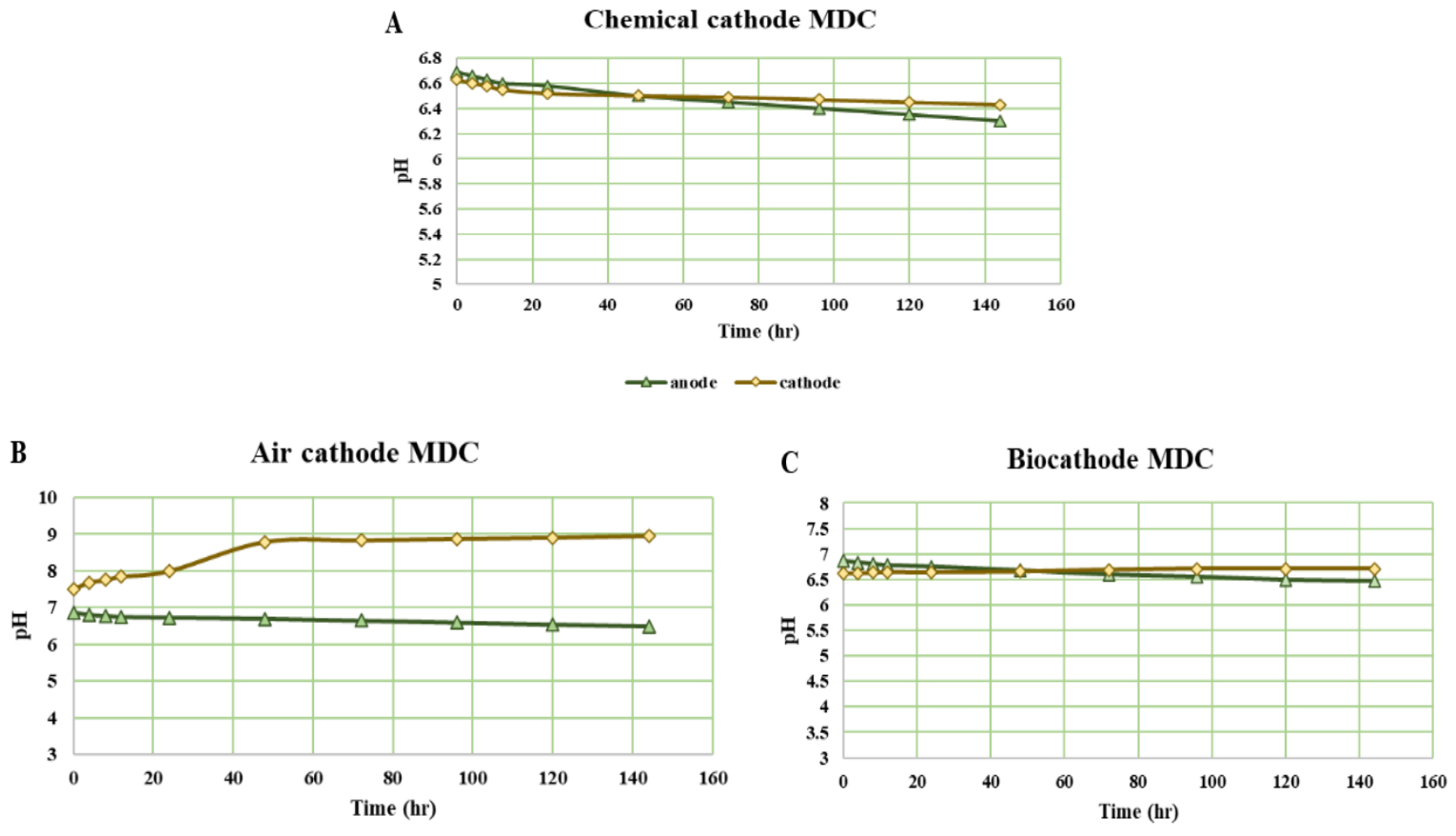

$\rightarrow$ anode $\leadsto$ cathode

Figure 7. The changes in the anolyte and catholyte's $\mathrm{pH}$ values for the three operation modes of the MDC.

\subsection{COD Removing Efficiency}

Fig. 8 shows the MDC's COD removal percentage with the three operation modes; the rates were $91.38,95.94,96.94 \%$ for the air cathode, chemical cathode, and biocathode MDC. It is clear that the highest percentage was with the biocathode MDC; it is the last mode was operated with a suitable thickness of bacteria biofilm layer in the anode chamber, and the ability of bacteria to degrade the organic matters was developed with time; while the lowest percentage was with the air cathode MDC the first mode was operated in this study. By comparing COD removal ratios in this study with the previous studies, this study is more efficient in COD removal. The COD removal in the study of (Bahareh and Veera, 2013) for biocathode and air cathode MDC were $65.6 \%$ and $56.6 \%$ respectively, while the percentage was $82.17 \%$ for biocathode MDC in the study of (Bahareh and Veera, 2015). 


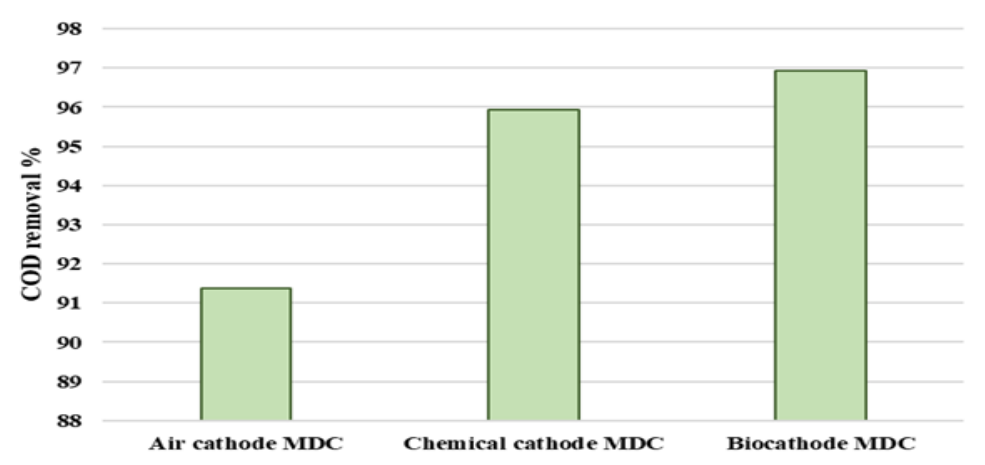

Figure 8. The COD removal percentage of the MDC with the three operation modes.

The relationship between the COD removal and the MDC's coulombic efficiency with the three operation modes is illustrated in Fig. 9. The highest CE values were 46.1, 24.2, and 24.6\% for the chemical cathode, air cathode, and biocathode MDC. The chemical cathode MDC had the highest $\mathrm{CE}$ value due to using a potent catalyst agent in the cathode chamber as an electron acceptor.

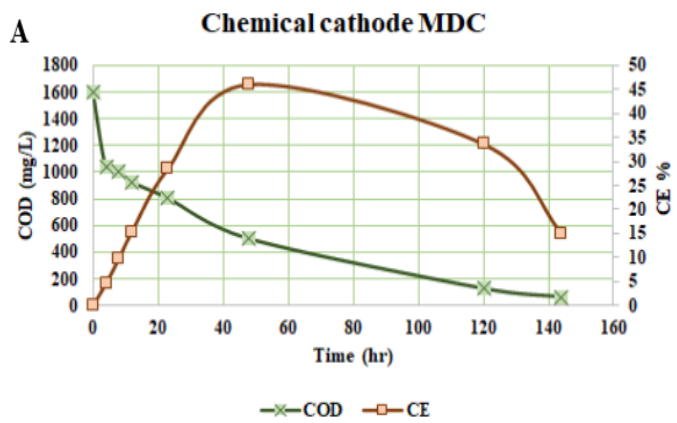

B

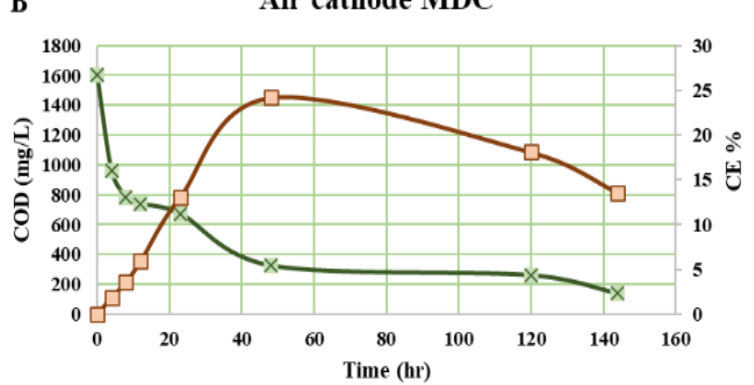

$-x-C O D-\square-C E$
C Biocathode MDC

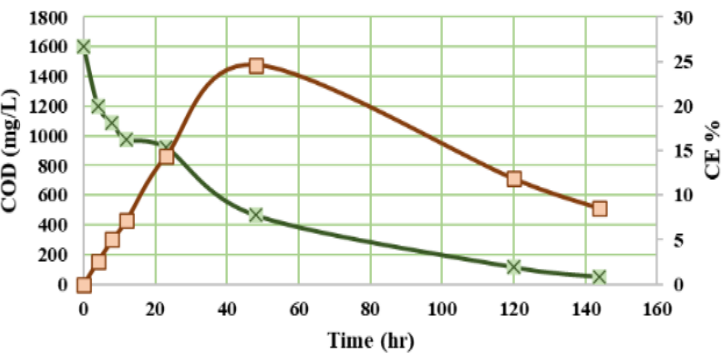

$-x-\mathrm{COD} \quad \square-\mathrm{CE}$

Figure 9. The COD removal and Coulombic Efficiency (CE) curves of the MDC with the three operation modes.

\section{CONCLUSIONS}

MDC has many ways to change the material used in the cathode chamber as the catholyte. This study was used three types of catholyte the first one chemical cathode by using Potassium Ferricyanide $\left(\mathrm{K}_{3}\left[\mathrm{Fe}(\mathrm{CN})_{6}\right]\right)$ solution as the catholyte, the second using an air pump to provide the oxygen to the water in the cathode chamber, and the third one utilizing Chlorella Vulgaris 
algae to provide cathode chamber with oxygen by the photosynthetic process. The results were as following: electrical power densities were $96.8,24.2$, and $19.91 \mathrm{~mW} / \mathrm{m}^{2}$, The desalination rates were 84.08, 86.11, 88.9 ppm/hr, and the percentages of COD removing were 95.94, 91.38, $96.94 \%$ for the chemical cathode, air cathode, and biocathode MDC, respectively. The most efficient type of MDC in this study in power production was the chemical cathode MDC, but it is the lowest sustainable. On the other hand, the biocathode MDC was the best in desalination process performance and both the air cathode and biocathode MDC are more sustainable and environmentally friendly, especially the biocathode MDC. The algae in biocathode can be cultivated and used in other applications like biodiesel; simultaneously, the algae in biocathode can treat many types of wastewater like oil refinery wastewater (Suhad et al., 2019).

\section{REFERENCES}

- Bahareh, K. and Veera, G. G. (2013), Photosynthetic microbial desalination cells (PMDCs) for clean energy, water, and biomass production, Environ. Sci. Processes Impacts, 15, 2178. https://doi.org/10.1039/C3EM00415E

- Bahareh K. and Veera G. Gude, (2015). Sustainable photosynthetic biocathode in microbial desalination cells, Chemical Engineering Journal, 262, 958-965. https://doi.org/10.1016/j.cej.2014.10.048

- Cao, X., Huang, X., Liang, P., Xiao, K., Zhou, Y., Zhang, X., and Logan, B.E., (2009). A new method for water desalination using microbial desalination cells. Environ Sci Technol., 43, 7148-7152. DOI: 10.1021/es901950j

- Friman, H., Schechter, A., Nitzan, Y., and Cahan, R. (2013). Phenol degradation in bioelectrochemical cells. Int. Biodeterior. Biodegrad. 84, 155-160. https://doi.org/10.1016/j.ibiod.2012.04.019

- Gude, V.G., (2015b). Energy positive wastewater treatment and sludge management. Edorium Journal of Waste Management 1, 10-15. DOI:10.5348/W01-2015-2-ED-2

- Gude, V.G. (2017). Desalination and water reuse to address global water scarcity. Rev.Environ. Sci. Biotechnol. 16 (4), 591-609. DOI:10.1007/s11157-017-9449-7

- Gude, V.G. (2018). Desalination of deep groundwater aquifers for freshwater Challenges and strategies. Groundwater for Sustainable Development, 6, 87-92. https://doi.org/10.1016/j.gsd.2017.11.002

- Gude, V.G. (2016). Wastewater treatment in microbial fuel cells-an overview. J. Clean. Prod. 122, 287-307. https://doi.org/10.1016/j.jclepro.2016.02.022

- Huang, L., Regan, J. M., and Quan, X., (2011). Electron transfer mechanisms, new applications, and performance of biocathode microbial fuel cells. Bioresour. Technol., 102, 316-323.https://doi.org/10.1016/j.biortech.2010.06.096

- Logan, B.E., Hamelers, B., Rozendal, R., Schrorder, U., Keller, J., Freguia, S., Aelterman, P., Verstraete, W., Rabaey, K., (2006). Microbial fuel cells: methodology and technology. Environ. Sci. Technol. 40, 17, 5181-5192. https://doi.org/10.1021/es0605016

- Luo, H., Xu, P., Jenkins, P. E., \& Ren, Z., (2012). Ionic composition and transport mechanisms in microbial desalination cells. Journal of Membrane Science, 409-410, 18-23.https://doi.org/10.1016/j.memsci.2012.02.059 
- Mathuriya, A.S. (2016). Novel microbial fuel cell design to operate with different wastewaters simultaneously. J. Environ. Sci. 42, 105-111. https://doi.org/10.1016/j.jes.2015.06.014

- Material safety data sheet (MSDS) for potassium ferricyanide.

- Ping, Q., Cohen, B., Dosoretz, C., and He, Z. (2013). Long-term investigation of fouling of cation and anion exchange membranes in microbial desalination cells, Desalination., 325, 48-55. https://doi.org/10.1016/j.desal.2013.06.025

- Pratiksha, S., Asheesh, K. Yadav, and Barada, K. Mishra, (2015). The effects of microbial fuel cell integration into a constructed wetland on the performance of constructed $\quad$ wetland. Bioresource Technology. https://doi.org/10.1016/j.biortech.2015.05.072

- Suhad S. Jaroo, Ghufran F. Jumaah, and Talib R. Abbas, (2019). Photosynthetic Microbial Desalination Cell to Treat Oily Wastewater Using Microalgae Chlorella Vulgaris. Civil Engineering Journal Vol. 5, No. 12, 2019, 2686-2699. http://dx.doi.org/10.28991/cej-2019-03091441

- Thomas, J. Arana, and Veera, G. Gude, (2018). A microbial desalination process with microalgae biocathode using sodium bicarbonate as an inorganic carbon source, International Biodeterioration \& Biodegradation 130, 91-97. https://doi.org/10.1016/j.ibiod.2018.04.003

- Werner, M., Logan, B. E., Saikaly, P. E., and Amy, G. E., (2013). Wastewater treatment, energy recovery, and desalination using a forward osmosis membrane in an air-cathode microbial osmotic fuel cell. J. Member Sci., 428, 116-122. https://doi.org/10.1016/j.memsci.2012.10.031 